\title{
Characterization of School Climate Perception in Mexican Middle School Students
}

\author{
Mercedes Gabriela Orozco-Solis ${ }^{1}$, Cecilia Colunga-Rodríguez ${ }^{1,2}$, Julio César Vázquez-Colunga1, \\ Claudia Liliana Vazquez-Juárez¹, Mario Ángel-González ${ }^{3}$, Sarah Lindstrom Johnson4, \\ Catherine P. Bradshaw ${ }^{5}$
}

${ }^{1}$ University Center for Health Sciences, University of Guadalajara, Guadalajara, Mexico

${ }^{2}$ Pediatric Hospital of the National West Medical Center at the Instituto Mexicano del Seguro Social (Mexican Social Security Institute, or IMSS), Guadalajara, Mexico

${ }^{3}$ University Center of Tonala and University Center for Health Sciences, University of Guadalajara, Guadalajara, Mexico

${ }^{4}$ Arizona State University, Tempe, USA

${ }^{5}$ University of Virginia, Charlottesville, USA

Email: gaby_orozco_13@hotmail.com

How to cite this paper: Orozco-Solis, M. G., Colunga-Rodríguez, C., Vázquez-Colunga, J. C., Vazquez-Juárez, C. L., Ángel-González, M., Johnson, S. L., \& Bradshaw, C. P. (2016). Characterization of School Climate Perception in Mexican Middle School Students. Psychology, 7, 1562-1574. http://dx.doi.org/10.4236/psych.2016.713151

Received: September 23, 2016

Accepted: November 8, 2016

Published: November 11, 2016

Copyright $\odot 2016$ by authors and Scientific Research Publishing Inc. This work is licensed under the Creative Commons Attribution International License (CC BY 4.0).

http://creativecommons.org/licenses/by/4.0/

(c) (i) Open Access

\begin{abstract}
School climate is a construct that shapes the interactions between school members and influences its development in different aspects. For the students, school climate perceptions have been linked to their academic, psychological, and behavioral development. Despite its relevance, there are only few studies of Mexican students exploring issues related to school climate. A transversal and descriptive study was developed. The 2211 participants were students from four public middle schools. They completed an adapted Spanish version of the MDS3 School Climate Survey, which was composed by 56 items that loaded onto three scales: engagement and school perception $(\alpha=.93)$, rules and equity $(\alpha=.90)$ and risk behavior $(\alpha=.92)$. The parents' consent was obtained through a waiver of active consent process. Frequencies, averages, standard deviation and Z-scores were calculated. Mann-Whitney $\mathrm{U}$ test and one-way analysis of variance (ANOVA) were used to explore differences in the school climate perceptions based on select student, familial, and school characteristics. Survey results were categorized into a three-level scale using Z-scores (low, medium, high). More than $10 \%$ of the participants scored in the low level, corresponding to a negative perception, while for the high level, the student connectedness subscale obtained one of the highest percentages (21.2\%), followed by the Risk behavior scale $(20.3 \%)$ and the school rules subscale (20.3\%). There were statistically significant differences found in the school climate perception for gender, age, mother school level and school shifts (i.e., AM vs. PM) variables. We can conclude that a high percentage of the participants have a negative perception of school climate and
\end{abstract}


consider that there are risk behaviors among the students in their schools. There were several significant differences in the school climate perceptions by sociodemographic, familial and school variables.

\section{Keywords}

School Climate, Perceptions, Middle School, Mexican Students

\section{Introduction}

School climate is defined by some authors as a multidimensional construct formed with the beliefs, values and attitudes shared by students, school staff and parents (Emmons, Corner, \& Haynes, 1996; Kuperminc, Leadbeater, Emmons, \& Blatt, 1997; DeRosier \& Newcity, 2005; Mitchell, Bradshaw, \& Leaf, 2010). It represents an important construct in school life because it stablishes the socially acceptable behavior in the school, shaping the interactions between the school members (students, teachers and parents) and influencing its development in different aspects. In the student's case, several studies had found that school climate perception plays an important role on their academic, psychological and behavioral development (Dotterer \& Lowe, 2011; Berger, Álamos, Milicic, \& Alcalay, 2013; Iachini, Buettner, Anderson, \& Reno, 2013; Burdick, 2013; Esselmont, 2014). For the staff, it affects topics such as work engagement and satisfaction, along with the perceived occupational health (Gregory, Cornell, \& Fan, 2012; Blömeke \& Klein, 2013; Song, Kim, Chai, \& Bae, 2014). For the parents, the level of participation and satisfaction towards the school are aspects also influenced by this construct (Goldkind \& Lawrence, 2013; Whitaker \& Hoover, 2013).

In the student's particular case, at an academic level, the research findings indicate that school climate perception associates with academic motivation and learning process, affecting school performance, satisfaction and engagement, which can relate to school dropout (Fan, Williams, \& Corkin, 2011; Liu \& Lu, 2011; Zullig, Collins, Ghani, Patton, Huebner, \& Ajamie, 2014). In the psychological aspects, the student's perception of this construct affects the sense of belonging to the school, modulates the association between academic stress and depressive symptoms, and predicts the generation of psychological alterations such as anxiety (Cemalcilar, 2010; Liu \& Lu, 2011; Liu, 2012). At a behavioral level, a negative perception of school climate between the students has been found associated with the increased of externalization problems, such as aggression, bullying, carrying weapons to school, substance use and gang belonging (Mehta, Cornell, Fan, \& Gregory, 2013; Bradshaw, 2013; Esselmont, 2014).

The school climate relevance in students' lives and development is noteworthy; it is important to consider because of its multidimensional character, the perception that the students have about this construct tends to be changing over the years, being influenced by sociodemographic, familial and school variables.

Sociodemographically, the studies identify that characteristics such as age, gender and ethnicity are factors that shape the student's school climate perception. About the 
age, the findings report a decrease tendency in the quality of the perceptions over the years, where the older students tend to have less positive perceptions than their youngest peers. For the gender variable, the females report better school climate that their classmates, specifically in aspects related to consistency and fairness of the school rules. Meanwhile, the members of minority groups tend to have lower perceptions of school climate (Way, Reddy, \& Rhodes, 2007; Mitchell, Bradshaw, \& Leaf, 2010; Wang, Selman, Dishion, \& Stormshak, 2010; Conderman, Walker, Neto, \& Kackar-Cam, 2013).

For the familial aspect, research suggests that characteristics such as belong to a family with negative climate at home, to have a single parent or parents with low levels of education, are factors related with a more negative perception of school climate by the student (Fan, Williams, \& Corkin, 2011).

At the school level, the students in the higher school grades that are being held back a grade or have changed schools are more prone to have negative perceptions of school climate. While the students that perceive good teacher-student relationships or a high principal's involvement in school, tend to have better school climate perceptions (Mitchell, Bradshaw, \& Leaf, 2010; Fan, Williams, \& Corkin, 2011; López de Mesa, Soto, Carvajal, \& Urrea, 2013).

School climate is an important element of school life, given that it shapes the interactions and affects the development of its members, although, despite its relevance, there are only few studies developed in our context about this topic, leaving unknown basic aspects, such as the perception that our students have about school climate. This lack of information disfavors the generation of future research about this subject and could affect the implementation of effective prevention and intervention strategies in our country. Because of this, the aim of this study was to describe the perceptions of school climate by Mexican middle school students.

\section{Research Setting}

These data were collected in the cities of Guadalajara and Tlaquepaque, both of them located in Jalisco, a state of the west-center area of Mexico. In the country, the school system is divided into a public and a private sector. In the public area, the school levels consider mandatory are kindergarten, elementary, middle school and high school (Nuño, 2016). This study was developed in middle schools from the public sector. The middle school consist of three different grades, attended by the students when they are around 12 to 15 years old. Most of the public middle schools, work in a two shift system, such that one set of students and teachers works in the morning from 7:00 am to 1:00 pm, while a different set works from 2:00 pm to 8:00 pm.

\section{Methodology}

\subsection{Participants}

Participants were the students from four public Jalisco middle schools. The schools were selected randomly from a list of schools that gather the requirement of having 
functional computer classrooms with internet access for the survey application. Eligible students were those who were enrolled regularly in the selected school and were able to use the computer equipment independently as the survey was administered online.

\subsection{Instrument}

The participants completed the online adapted Spanish version of the U.S. based MDS3 School Climate Survey, which was originally created in English (Bradshaw, Waasdorp, Debnam, \& Lindstrom, 2014), and translated, adapted and validated to Spanish by the Mexico-based team. The translated version was back-translated to English by members of the U.S. team prior to the adaptation and validation. The version applied consisted of an initial page with sociodemographic (gender and age), familial (mother school level) and school data (grade and school shift attended). The survey included 56 items, which in this sample an exploratory factor analysis indicated loaded onto three scales: Engagement and school perception $(\alpha=.93)$, rules and equity $(\alpha=.90)$, and risk behavior $(\alpha=.92)$.

The engagement and school perception scale includes questions about the school engagement and the connections between the school members. It includes 26 items, which are grouped into five subscales: school engagement, student connectedness, teacher connectedness, parent connectedness and safety perception in school. The answer options were on a four-point Likert scale, going from totally agree to totally disagree.

The rules and equity scale has 24 items that regard about the implementation and control of school rules, culture of equity and behavioral disorder situations. The scale is divided into four subscales: school rules, equity, school facilities comfort and disorder situations. The answer options are in the format mentioned before.

The risk behavior scale does not include any subscales. It has six questions about the how much is a problem in their school the existence of behaviors such as substances use and aggression. The answer options are in a four point Likert scale, going from large problem to not a problem.

\subsection{Data Collection}

Prior to completing the survey, parental consent was obtained thru a waiver of active parental consent process. The students whose parents did not approve of participation were excluded from the study. The survey was administered in the schools' computer labs during regular school hours. The participating students attended a 30 minutes session coordinated by the lead researcher. The purpose of the survey, along with the other ethical aspects related to their confidential and voluntary participation, were explained. Those students who decided to not participate in the research returned to their classrooms. After students had any questions answered, the researcher remained present during the administration to answer any additional questions that came up during completion of the survey. No material or scholarly incentive was provided to the students once they finished the survey. 


\subsection{Data Analysis}

An excel 2010, database was obtained automatically through the survey platform. The data were analyzed in SPSS version 20.0. Frequencies, averages and standard deviation were calculated for the sociodemographic and school variables. Z-score were obtained from the total scores for each of the three survey scales and 16 subscales. A categorization of the scores was develop, taking as low, the values lower than minus one standard deviation (SD); as medium, the Z-scores distributed from minus one SD to plus one $\mathrm{SD}$, and high, for the values higher than plus one SD. Using the obtained categorization, frequencies and percentages were calculated for each scale and subscale. Finally, we examined the extent to which the scale scores varied as a function of sociodemographic, familial and school variables. We controlled for gender and school shift, using the Mann-Whitney U test. We also controlled for the student's age and mother's education level using one-way analysis of variance (ANOVA).

\subsection{Ethic Considerations}

The procedures for collecting the data were reviewed and approved by the Ethics Committee Review Board of the Interinstitutional Doctorate in Psychology at the University of Guadalajara.

\section{Results}

\subsection{Sociodemographic Characteristics}

The final sample consisted of 2211 students. The mean age was 13.6 years (SD 1) with a range from 12 to 18 . For the gender variable, 51\% (1059) were female and 49\% (1021) male. In the mother school level of education, 66.6\% (1474) did not finished high school, $21.8 \%$ (483) finished high school, 5.2\% (115) when to college, but did not graduate, and $6.3 \%$ (139) graduated from college. The distribution for the school variables (school grade and shift) is presented in Table 1.

\subsection{Perception of School Climate}

Using Z-scores for the survey scale and subscales, the data were divided in three levels: low, medium and high based on the students' overall perception of school climate. The results are presented in Table 2.

Table 1. Sample distribution for the school grade and school shift variables.

\begin{tabular}{|c|c|c|c|c|c|}
\hline & & \multicolumn{4}{|c|}{ School shift } \\
\hline & & \multicolumn{2}{|c|}{ AM shift } & \multicolumn{2}{|c|}{ PM shift } \\
\hline & & $\mathrm{n}$ & $\%$ & $\mathrm{n}$ & $\%$ \\
\hline \multirow{3}{*}{ School grade } & First grade & 487 & $21.9 \%$ & 399 & $17.9 \%$ \\
\hline & Second grade & 379 & 17.1 & 376 & 17 \\
\hline & Third grade & 345 & 15.6 & 225 & 10.1 \\
\hline
\end{tabular}

$\mathrm{n}=$ frequency, sample $=2211$. 
Table 2. Distribution of school climate perceptions reported by middle school students.

\begin{tabular}{ccccccc}
\hline \multirow{2}{*}{ School climate } & \multicolumn{5}{c}{ Levels of distribution } \\
\cline { 2 - 7 } & \multicolumn{2}{c}{ Low } & Medium & High \\
\hline Engagement and school perception & 320 & 14.5 & 1548 & 70 & 343 & 15.5 \\
School engagement & 261 & 11.8 & 1738 & 78.6 & 212 & 9.6 \\
Student connectedness & 358 & 16.2 & 1384 & 62.6 & 469 & 21.2 \\
Teacher connectedness & 321 & 14.5 & 1618 & 73.2 & 272 & 12.3 \\
Parent connectedness & 347 & 15.7 & 1604 & 72.5 & 260 & 11.8 \\
Safety perception in school & 274 & 12.4 & 1624 & 73.5 & 313 & 14.2 \\
Rules and equity & 290 & 13.1 & 1555 & 70.3 & 366 & 16.1 \\
School rules & 318 & 14.4 & 1445 & 65.4 & 448 & 20.3 \\
Equity & 310 & 14 & 1560 & 70.6 & 341 & 15.4 \\
School facilities comfort & 328 & 14.8 & 1482 & 67 & 401 & 18.1 \\
Disorder situations & 326 & 14.7 & 1500 & 67.8 & 385 & 17.4 \\
Risk behavior & 533 & 24.1 & 1230 & 55.6 & 448 & 20.3 \\
\hline
\end{tabular}

$\mathrm{n}=$ frequency, sample $=2211$.

For youth in the low perceptions of climate, every scale and subscale presented percentages higher than $10 \%$; for the medium level the distribution was very similar between the subscales, while, for the high level, the Student connectedness obtained one of the highest percentages, followed closely from the Risk behavior scale.

\subsection{School Climate Statistical Differences Based in Sociodemographic, Familial and School Variables}

The statistical differences existing in the school climate perception were stablished using Mann-Whitney U test for gender and school shift variables (Table 3). For gender, significant statistical differences between the male and female school climate perception were observed in the scale engagement and school perception $(<.01)$ and for its subscales school engagement $(<.05)$ and teacher connectedness $(<.01)$, presenting a more positive perception for the females. Meanwhile, the males' scores indicate a more positive perception in the subscale student connectedness $(<.01)$, along with the rules and equity subscale: disorder situations $(<.01)$.

For school shift, the morning shift students presented a more positive perception, having statistically significant difference for all the scales and the subscales student connectedness $(<.01)$, teacher connectedness $(<.01)$, safety perception in school $(<.05)$, equity $(<.01)$ and school facilities comfort $(<.01)$.

One-way analysis of variance (ANOVA) was used to compare the school climate perception for the age and mother school level variables. For the age variable, four comparison groups were delimitated: 12 years old (14.8\%), 13 years old (29.1\%), 14 
Table 3. School climate scores compared according to student's age.

\begin{tabular}{|c|c|c|c|c|c|c|}
\hline \multirow{3}{*}{ School climate } & \multicolumn{3}{|c|}{ Gender } & \multicolumn{3}{|c|}{ School shift } \\
\hline & \multicolumn{2}{|c|}{ Mean } & \multirow{2}{*}{$P$-value } & \multicolumn{2}{|c|}{ Mean } & \multirow{2}{*}{$P$-value } \\
\hline & Male & Female & & Morning & Afternoon & \\
\hline Engagement and school perception & -.12 & .04 & .000 & .06 & -.08 & .000 \\
\hline School engagement & -.10 & .03 & .015 & .01 & -.01 & .401 \\
\hline Student connectedness & .05 & -.20 & .000 & .07 & -.09 & .000 \\
\hline Teacher connectedness & -.08 & .03 & .002 & .05 & -.07 & .001 \\
\hline Parent connectedness & -.09 & .01 & .060 & .02 & -.03 & .187 \\
\hline Safety perception in school & -.06 & -.03 & .973 & .02 & -.03 & .044 \\
\hline Rules and equity & -.04 & -.18 & .006 & .05 & -.06 & .012 \\
\hline School rules & -.08 & -.03 & .429 & .01 & -.01 & .285 \\
\hline Equity & -.02 & -.02 & .704 & .05 & -.06 & .002 \\
\hline School facilities comfort & -.09 & -.03 & .657 & .08 & -.09 & .000 \\
\hline Disorder situations & -.02 & -.20 & .000 & -.01 & .01 & .527 \\
\hline Risk behavior & -.07 & -.12 & .222 & .04 & -.05 & .021 \\
\hline
\end{tabular}

Bolded values indicate significant differences at $P<.05$.

years old (32.3\%), 15 years old and more (23.8\%). The findings indicated that the 12 year old group reported a more positive perception in most of the scales and subscales. Only the risk behavior scale presented higher values for the 15 and more group. The statistically significant differences between the 12 and 15 years old groups, were the most common, the rest of the group differences are presented in Table 4.

For the mother's highest level of schooling/education, which was a proxy for socioeconomic status, the comparison groups were: did not finished high school (DFH); completed high school $(\mathrm{H})$; did not finished college (DFC), and college degree (CD). The results showed that the students whose mothers had a college degree (i.e., CD group) perceived the school climate to be most favorable across most of the scales and subscales; however, only in the parent connectedness to school that the students with mothers in the DFH group obtained higher scores, but these effects did not reach statistical significance. The differences between the groups defined by DFH and $\mathrm{H}$ appeared to be the most different from each other (Table 5).

\section{Discussion}

The aim of this study was to describe the extent to which student and school characteristics were associated with perceptions of school climate among Mexican middle school students. We found statistically significant differences observed in the school climate perception based on the sociodemographic, familial and school variables. Specifically, we created low, medium and high levels groups based on the data distribution according to standard deviations, with the goal of characterizing variations in the 
Table 4. School climate scores compared according to student's age.

\begin{tabular}{|c|c|c|c|c|c|c|}
\hline \multirow{3}{*}{ School climate } & \multicolumn{6}{|c|}{ Age } \\
\hline & \multicolumn{4}{|c|}{ Mean \pm SD } & \multirow{2}{*}{$\mathrm{F}$} & \multirow{2}{*}{$P$-value } \\
\hline & 12 & 13 & 14 & 15 and more & & \\
\hline $\begin{array}{l}\text { Engagement and school } \\
\text { perception }\end{array}$ & $.13 \pm 1.04$ & $.09 \pm .97$ & $-.1 \pm 1.01^{\star, \star \star}$ & $-.16 \pm 1^{\star, * *}$ & 10.06 & .000 \\
\hline School engagement & $-.04 \pm .99$ & $.07 \pm .99$ & $-.09 \pm 1.08^{\star *}$ & $-.03 \pm .96$ & 3.19 & .023 \\
\hline Student connectedness & $.13 \pm .97$ & $-.03 \pm 1$ & $-.11 \pm .95^{\star}$ & $-.13 \pm 1^{\star}$ & 6.02 & .000 \\
\hline Teacher connectedness & $.05 \pm .95$ & $-.03 \pm 1.05$ & $.008 \pm .97$ & $-.09 \pm 1.09$ & 1.60 & .186 \\
\hline Parent connectedness & $.11 \pm .9$ & $.06 \pm 1$ & $-.10 \pm 1.01^{*, *}$ & ${ }^{*}-.13 \pm 1.08^{\star, * *}$ & 7.02 & .000 \\
\hline Safety perception in school & $.08 \pm 1$ & $.01 \pm 1.02$ & $-.04 \pm .94$ & $-.14 \pm 1.06^{\star, * *}$ & 3.92 & .008 \\
\hline Rules and equity & $.05 \pm .92$ & $-.06 \pm .94$ & $-.12 \pm .91^{*}$ & $-.16 \pm .95^{\star}$ & 4.06 & .007 \\
\hline School rules & $.11 \pm 1.06$ & $.01 \pm .96$ & $-.08 \pm .97^{\star}$ & $-.17 \pm 1.02^{\star * * *}$ & 6.03 & .000 \\
\hline Equity & $.07 \pm 1.08$ & $.02 \pm .95$ & $-.03 \pm 1.03$ & $-.08 \pm 1.04$ & 2.04 & .106 \\
\hline School facilities comfort & $.08 \pm 1.09$ & $-.04 \pm 1$ & $-.08 \pm .95$ & $-.10 \pm .99^{*}$ & 2.78 & .040 \\
\hline Disorder situations & $-.18 \pm 1.03$ & $3-.08 \pm .90$ & $-.11 \pm .90$ & $-.01 \pm .92$ & 2.22 & .083 \\
\hline Risk behavior & $-.09 \pm 1.05$ & $5-.17 \pm .98$ & $-.06 \pm .91$ & $.03 \pm .91^{* *}$ & 4.23 & .005 \\
\hline
\end{tabular}

Note: The age values are expressed in student years. ${ }^{\star} P<.05$ compared with 12 years old students. ${ }^{*} P<.05$ compared with 13 years old students. ${ }^{* *} P<.05$ compared with 14 years old students. ${ }^{* * *} P<.05$ compared with 15 years old students.

Table 5. School climate scores compared according to student's mother school level.

\begin{tabular}{|c|c|c|c|c|c|c|}
\hline \multirow{3}{*}{ School climate } & \multicolumn{6}{|c|}{ Mother school level } \\
\hline & \multicolumn{4}{|c|}{ Mean \pm SD } & \multirow{2}{*}{$\mathrm{F}$} & \multirow{2}{*}{$P$-value } \\
\hline & DFH & $\mathrm{H}$ & $\mathrm{DFC}$ & $\mathrm{CD}$ & & \\
\hline $\begin{array}{l}\text { Engagement and school } \\
\text { perception }\end{array}$ & $-.009 \pm .99$ & $.02 \pm 1$ & $-.22 \pm 1.11^{* * * *}$ & $.16 \pm .92$ & 3.28 & .020 \\
\hline School engagement & $-.009 \pm 1.02$ & $-.001 \pm .96$ & $-.11 \pm 1.25$ & $.12 \pm .88$ & 1.25 & .287 \\
\hline Student connectedness & $.03 \pm .99^{* *}$ & $-.10 \pm 1$ & $-.01 \pm 1.04$ & $.15 \pm 1.05^{\star *}$ & 3.41 & .017 \\
\hline Teacher connectedness & $-.006 \pm 1.02$ & $.03 \pm .93$ & $-.16 \pm 1.11$ & $.06 \pm .96$ & 1.39 & .243 \\
\hline Parent connectedness & $.02 \pm .99$ & $-.03 \pm 1.04$ & $.008 \pm .94$ & $.01 \pm .97$ & .38 & .765 \\
\hline Safety perception in school & $-.009 \pm .98$ & $.07 \pm 1$ & $-.17 \pm 1.09$ & $.10 \pm .96$ & 2.57 & .052 \\
\hline Rules and equity & $.04 \pm 1.04^{* *}$ & $-.09 \pm .89$ & $-.07 \pm 1.09$ & $.14 \pm .93$ & 3.47 & .016 \\
\hline School rules & $.02 \pm .99^{* * *}$ & $-.01 \pm 1$ & $-.33 \pm 1.17$ & $.15 \pm .97$ & 5.56 & .001 \\
\hline Equity & $.008 \pm .97$ & $.009 \pm 1.01$ & $-.04 \pm 1.03$ & $.05 \pm 1.05$ & .18 & .910 \\
\hline School facilities comfort & $.002 \pm 1$ & $-.04 \pm 1.02$ & $.003 \pm .97$ & $.19 \pm .96$ & 2.11 & .096 \\
\hline Disorder situations & $.04 \pm 1^{\star \star}$ & $-.10 \pm .95$ & $.10 \pm .94$ & $.001 \pm 1$ & 3.17 & .023 \\
\hline Risk behavior & $.02 \pm 1.01^{\star *}$ & $-.13 \pm .98^{\star \star \star}$ & $.16 \pm 1.09$ & $.04 \pm .95$ & 4.45 & .004 \\
\hline
\end{tabular}

Note: DFH, did not finished high school; H, completed high school; DFC, did not finished college; CD, college degree. ${ }^{\star} P<.05$ compared with DFH group. ${ }^{*} P<.05$ compared with H group. ${ }^{\star *} P<.05$ compared with DFC group. ${ }^{* * *} P<.05$ compared with $\mathrm{CD}$ group. 
students' school climate perceptions, were a low level corresponds to a more negative perception, while the high level refers to a positive perception about the aspect studied. In this matter, the findings indicate that for the low level, all the scales and subscales obtained scores higher than $10 \%$, which is relevant considering that from the public health approach, percentages over $10 \%$ could be considered as a risk factor for the development of different problems in the population. So, from the epidemiological point of view, it would be possible to say that the Mexican middle school students might be at risk to develop future academic, psychologic or behavioral problems because of the negative perception of the school climate dimensions (Zullig, Collins, Ghani, Patton, Huebner, \& Ajamie, 2014; Burdick, 2013; Esselmont, 2014).

Another important finding was that a high percentage of the participants scored in the high level for the risk behavior scale. It is important to note that this scale was scored such that higher scores indicating greater risk behavior in the school, such as substance use, aggression and gang affiliation. This finding regarding the high presence of risk behavior among the middle school students is consistent with several prior studies which have suggested that Mexico adolescents experience high rates of substances use and aggressive behavior in the school; this in turn may increase their own risk and pose as a risk to other students in the school (Villatoro et al., 2012; Vega, González, Valle, Flores, \& Vega, 2013).

Regarding the differences between the school climate perception, the findings indicate the existence of statistical significant differences for the gender, age, mother school level and school shift variables. In regard to gender, the results indicated that the females reported higher school engagement and connections with teachers, whereas the males presented a more positive perception in the aspects related to connection with other students and disorder situations. This finding differs from other studies that reported that males tend to have a more negative perception of the school rules and student relationships compared than female students (Mitchell, Bradshaw, \& Leaf, 2010; Wang, Selman, Dishion, \& Stormshak, 2010; Fan, Williams, \& Corkin, 2011). The discrepancy could be explained from a cultural perspective, such that it is possible that in our context the female students might have more difficulties in the interactions with their peers, whereas the male students may perceive more disorder situations in the school (Vega, González, Valle, Flores, \& Vega, 2013).

Not surprisingly, the age variable followed a similar trend, whereby younger students tended to have a more positive perception of almost all the school climate scales and subscales; these results are consistent with several previous studies reporting a tendency by which school climate perceptions becomes more negative as students get older (Fan, Williams, \& Corkin, 2011; Conderman, Walker, Neto, \& Kackar-Cam, 2013; López de Mesa, Soto, Carvajal, \& Urrea, 2013).

For the maternal education level, we found that students whose mothers had a higher educational level reported a more positive school climate perception. This finding is supported by other research which has found that the parents' own level of education may influence their children's skills to adapt and interact with others in environments 
such as the school (Fan, Williams, \& Corkin, 2011; Jansen et al., 2012).

Finally, the school shift (i.e., AM vs. PM) findings suggested that the morning shift students had significantly better perceptions of the school climate than the students from the afternoon shift. This is an important result, because in Mexico, most of the public elementary and middle schools function with a two shift system, where both shifts are assumed to work the same way and obtain similar results. These findings suggest that it is important to take into consideration this difference across school shifts, which are rather robust for school climate but may also signal other differences in student outcomes, including academic and behavioral indicators, such as school dropout and low academic achievement.

\section{Conclusion}

School climate is an important construct for the development of the students and the rest of the members of the school community. The research findings indicate that it is probable that a high percentage of the Mexican middle school students have a negative school climate perception, reporting a high presence of risk conducts among the students. These results, although there is a need further analysis, reflect the importance of develop future research about the school climate topic with Mexican students, considering that this is a construct that has implications for the students' academic, psychological and behavioral development.

Significant differences were found in the school climate perception for the sociodemographic, familial and school variables. Regarding the gender, we observed that the females perceived better the school engagement and teacher connections, while the males had a more positive perception of aspects related to student connections and disorder situation. This finding could be indicating that there are important differences in the way females and males interact with the school elements, characteristics that need to be taken into consideration for the development of other studies and prevention strategies, because they might favor the generation of other problems that affect the students.

Regarding the age variable, the results indicated that the younger students have a more positive school climate perception compared to their older peers. This finding suggests that the students in the higher grades of middle school could be considered as a risk population, because they have greater chances to have a less favorable school climate perception.

For the mother school level, we observe that those students whose mothers had the higher school levels presented more positive perceptions. The result is relevant because it indicates that they might be necessary to provide greater supports for the students and families where the mothers have lower educational levels, considering this is variable that has been associated with other problems such as school dropout, bullying, etc.

The results for the school shift variable indicate that the AM students reported better perceptions that the ones in the PM shift. This is an important result because, despite the fact that in our country most of the public schools work in a two shift system, there 
are scares studies that focus in the differences among the students, teachers and parents from both shifts, and, in the way this differences influence the student's outcomes in different areas.

\section{Acknowledgements}

To the University of Guadalajara and the Consejo Nacional de Ciencia y Tecnologia (National Science and Technology Council CONACyT) for the support provided thru a national scholarship for the development of the doctoral dissertation from which this study was derived. To the Maryland State Department of Education and Sheppard Pratt Health System for the support provided for the development of this research through the Maryland Safe and Supportive Schools Project. To the Secretaria de Educacion Jalisco (Jalisco Ministry of Education SEJ) for the facilities provided for the data collection. And to the administrators, teachers and students who participated in this research.

\section{Conflict of Interest Declaration}

The authors declare that there is no conflict of interests with this research, the authorship and/or the publication of this paper.

\section{References}

Berger, C., Álamos, P., Milicic, N., \& Alcalay, L. (2013). Academic Performance and Personal and Contextual Dimensions of Socioemotional Learning: Evidence of Its Association in Chilean Students. Universitas Psychologica, 13, 627-638.

Blömeke, S., \& Klein, P. (2013). When Is a School Environment Perceived as Supportive by Beginning Mathematics Teachers? Effects of Leadership, Trust, Autonomy and Appraisal on Teaching Quality. International Journal of Science and Mathematics Education, 11, 1029-1048. http://dx.doi.org/10.1007/s10763-013-9424-x

Bradshaw, C. (2013). Preventing Bullying through Positive Behavioral Interventions and Supports (PBIS): A Multitiered Approach to Prevention and Integration. Theory into Practice, 52, 288-295. http://dx.doi.org/10.1080/00405841.2013.829732

Bradshaw, C., Waasdorp, T., Debnam, K., \& Lindstrom, S. (2014). Measuring School Climate in High Schools: A Focus on Safety, Engagement, and the Environment. Journal of School Health, 84, 593-604. http://dx.doi.org/10.1111/josh.12186

Burdick, J. (2013). School Violent Crime and Academic Achievement in Chicago. American Sociological Association, 86, 343-361. http://dx.doi.org/10.1177/0038040713494225

Cemalcilar, Z. (2010). Schools as Socialization Contexts: Understanding the Impact of School Climate Factors on Students' Sense of School Belonging. Applied Psychology: An International Review, 59, 243-272. http://dx.doi.org/10.1111/j.1464-0597.2009.00389.x

Conderman, G., Walker, D., Neto, J., \& Kackar-Cam, H. (2013). Student and Teacher Perceptions of Middle School Climate. The Clearing House, 86, 184-189. http://dx.doi.org/10.1080/00098655.2013.802214

DeRosier, M., \& Newcity, J. (2005). Students' Perceptions of the School Climate: Implications for School Safety. Journal of School Violence, 4, 3-19. http://dx.doi.org/10.1300/J202v04n03_02

Dotterer, A., \& Lowe, K. (2011). Classroom Context, School Engagement, and Academic Achievement in Early Adolescence. Journal of Youth and Adolescence, 40, 1649-1660. 
http://dx.doi.org/10.1007/s10964-011-9647-5

Emmons, C., Comer, J., \& Haynes, N. (1996). Translating Theory into Practice: Comer's Theory of School Reform. In J. P. Comer, N. M. Haynes, E. Joyner, \& M. Ben-Avie (Eds.), Rallying the Whole Village. New York: Teachers College Press.

Esselmont, C. (2014). Carrying a Weapon to School: The Roles of Bullying Victimization and Perceived Safety. Deviant Behavior, 35, 215-232.

http://dx.doi.org/10.1080/01639625.2013.834767

Fan, W., Williams, C., \& Corkin, D. (2011). A Multilevel Analysis of Student Perceptions of School Climate: The Effect of Social and Academic Risk Factors. Psychology in the Schools, 48, 632-647. http://dx.doi.org/10.1002/pits.20579

Goldkind, L., \& Farmer, L. (2013). The Enduring Influence of School Size and School Climate on Parents' Engagement in the School Community. School Community Journal, 23, 223-243.

Gregory, A., Cornell, D., \& Fan, X. (2012). Teacher Safety and Authoritative School Climate in High Schools. American Journal of Education, 118, 401-425. http://dx.doi.org/10.1086/666362

Iachini, A., Buettner, C., Anderson-Butcher, D., \& Reno, R. (2013). Exploring Students' Perceptions of Academic Disengagement and Reengagement in a Dropout Recovery Charter School Setting. Children \& schools, 35, 113-120. http://dx.doi.org/10.1093/cs/cdt005

Jansen, P., Verlinden, M., Berkel, A., Mieloo, C., Ende, J., Veenstra, R., \& Tiemeier, H. (2012). Prevalence of Bullying and Victimization among Children in Early Elementary School: Do Family and School Neighbourhood Socioeconomic Status Matter? BMC Public Health, 12, 1-18. http://dx.doi.org/10.1186/1471-2458-12-494

Kuperminc, G., Leadbeater, B., Emmons, C., \& Blatt, S. (1997). Perceived School Climate and Difficulties in the Social Adjustment of Middle School Students. Applied Developmental Science, 1, 76-88. http://dx.doi.org/10.1207/s1532480xads0102_2

Liu, Y., \& Lu, Z. (2011). Chinese High School Students' Academic Stress and Depressive Symptoms: Gender and School Climate as Moderators. Stress and Health, 28, 340-346. http://dx.doi.org/10.1002/smi.2418

Liu, Y. (2012). Students' Perceptions of School Climate and Trait Test Anxiety. Psychological Reports, 111, 761-764. http://dx.doi.org/10.2466/11.10.21.PR0.111.6.761-764

López de Mesa, C., Carvajal, C., Soto, M., \& Urrea, P. (2013). Factors Associated with School Coexistence in Adolescents. Educ. Educ., 16, 383-410. http://dx.doi.org/10.5294/edu.2013.16.3.1

Mehta, S., Cornell, D., Fan, X., \& Gregory, A. (2013). Bullying Climate and School Engagement in Ninth-Grade Students. Journal of School Health, 83, 45-52. http://dx.doi.org/10.1111/j.1746-1561.2012.00746.x

Mitchell, M., Bradshaw, C., \& Leaf, P. (2010). Student and Teacher Perceptions of School Climate: A Multilevel Exploration of Patterns of Discrepancy. Journal of School Health, 80, 271-279. http://dx.doi.org/10.1111/j.1746-1561.2010.00501.x

Nuño, A. (13 July 2016). The School Model 2016.

https://www.gob.mx/modeloeducativo2016/articulos/introduccion-46873

Song, J., Kim, W., Chai, D., \& Bae, S. (2014) The Impact of an Innovative School Climate on Teachers' Knowledge Creation Activities in Korean Schools: The Mediating Role of Teachers' Knowledge Sharing and Work Engagement. Journal of Educational Policy, 11, 179-203.

Vega, M., González, G., Valle, M., Flores, M., \& Vega, A. (2013). School Harassment at the Metropolitan Area of Guadalajara, Mexico: Prevalence and Associated Factors. Salud Colectiva, 9, 183-194. http://www.scielo.org.ar/scielo.php?pid=S1851- 
Villatoro, J., Medina, M., Fleiz, C., Moreno, M., Oliva, N., Bustos, M., Fregoso, D., Gutiérrez, M., \& Amador, N. (2012). Drug Use in Mexico: Results from the National Addiction Survey, 2011. Salud Mental, 35, 447-457.

Wang, M. T., Selman, R. L., Dishion, T. J., \& Stormshak, E. A. (2010). A Tobit Regression Analysis of the Covariation between Middle School Students' Perceived School Climate and Behavioral Problems. Journal of Research on Adolescence, 20, 274-286.

http://dx.doi.org/10.1111/j.1532-7795.2010.00648.x

Way, N., Reddy, R., \& Rhodes, J. (2007) Students' Perceptions of School Climate during the Middle School Years: Associations with Trajectories of Psychological and Behavioral Adjustment. American Journal of Community Psychology, 40, 194-213.

http://dx.doi.org/10.1007/s10464-007-9143-y

Whitaker, M., \& Hoover, K. (2013). School Influences on Parents' Role Beliefs. The Elementary School Journal, 114, 73-99. http://dx.doi.org/10.1086/671061

Zullig, K., Collins, R., Ghani, N., Patton, J., Huebner, E., \& Ajamie, J. (2014). Psychometric Support of the School Climate Measure in a Large, Diverse Sample of Adolescents: A Replication and Extension. Journal of School Health, 84, 82-90. http://dx.doi.org/10.1111/josh.12124

Submit or recommend next manuscript to SCIRP and we will provide best service for you:

Accepting pre-submission inquiries through Email, Facebook, LinkedIn, Twitter, etc. A wide selection of journals (inclusive of 9 subjects, more than 200 journals)

Providing 24-hour high-quality service

User-friendly online submission system

Fair and swift peer-review system

Efficient typesetting and proofreading procedure

Display of the result of downloads and visits, as well as the number of cited articles Maximum dissemination of your research work

Submit your manuscript at: http://papersubmission.scirp.org/

Or contact psych@scirp.org 